\title{
An intermittent schedule is better than continuous regimen of antimonial therapy for cutaneous leishmaniasis in the municipality of Rio de Janeiro, Brazil
}

\author{
O esquema de tratamento antimonial intermitente é superior ao \\ contínuo na terapia da leishmaniose cutânea no \\ município do Rio de Janeiro, Brasil
}

Rilza Beatriz G. de Azeredo-Coutinho' ${ }^{1}$ and Sergio C.F. Mendonça ${ }^{1}$

\begin{abstract}
This study reviews a series of cutaneous leishmaniasis cases diagnosed and treated in outpatient units in the municipality of Rio de Janeiro, where the intermittent schedule of antimonial therapy was replaced by the continuous regimen. Both schedules were based on daily intramuscular injections of pentavalent antimonial. Forty-nine subjects received the intermittent regimen, consisting of three ten-day series alternated with ten-day rest intervals whereas seventy-one patients received the continuous regimen during 20 consecutive days. The study groups had similar composition regarding age, sex and clinical condition. The cure rate was significantly higher in the group receiving the intermittent schedule than in the group receiving continuous therapy (89.8\% vs 63.3\%). Moreover, loss to follow-up was significantly more frequent in the group receiving continuous therapy (19.7\% vs $4.1 \%$ in the intermittent therapy). Under field conditions, the intermittent regimen provided higher effectiveness and adherence than the continuous schedule.
\end{abstract}

Key-words: American cutaneous leishmaniasis. Leishmania braziliensis. Antimonial therapy.

Resumo Este estudo apresenta uma revisão de uma série de pacientes com leishmaniose cutânea diagnosticados e tratados em Centros Municipais de Saúde do Rio de Janeiro, onde o esquema intermitente de tratamento antimonial foi substituído pelo esquema contínuo. Ambos os esquemas terapêuticos foram baseados em injeções intramusculares diárias de antimonial pentavalente. Quarenta e nove indivíduos receberam o esquema intermitente, constituído de três séries de dez dias alternadas com intervalos de dez dias de descanso, enquanto que setenta e um indivíduos receberam o esquema contínuo durante 20 dias consecutivos. Os dois grupos tinham composição semelhante quanto à idade, sexo e quadro clínico. A taxa de cura foi significativamente maior no grupo que recebeu o tratamento intermitente do que no que recebeu o esquema contínuo (89,8\% vs 63,3\%). Além disto, a perda do acompanhamento dos pacientes foi significativamente maior no grupo que recebeu o tratamento contínuo (19,7\% vs 4,1\% no grupo de terapia intermitente). Em condições de campo, o tratamento intermitente proporcionou maior efetividade e adesão do que o esquema contínuo.

Palavras-chaves: Leishmaniose cutânea americana. Leishmania braziliensis. Terapia antimonial.

The American cutaneous leishmaniases are a group of diseases endemic in many American countries, caused by different species of the protozoan parasite Leishmania $^{10}$. In Brazil, most of the human infections are due to $L$. (Viannia) braziliensis ${ }^{9}$.

Parenteral pentavalent antimonials are still the first choice therapy for leishmaniasis ${ }^{218}$. In spite of being the first-line drugs, they have potential toxicity to the heart, liver, pancreas and kidneys ${ }^{718}$. Therapy regimens are usually prolonged and consecutive intramuscular injections are painful, but often necessary under field conditions ${ }^{18}$.

During the last twenty years, hundreds of patients with American tegumentary leishmaniasis have been treated in public outpatient units in the endemic areas located in the surroundings of Rio de Janeiro. An intermittent regimen of antimonial therapy has been adopted during most of this period. The standard

\footnotetext{
1. Departamento de Imunologia do Instituto Oswaldo Cruz da Fundação Oswaldo Cruz, Rio de Janeiro, RJ. Financial support: CNPq.

Address to: Dr. Sergio Mendonça. Dept ${ }^{\circ}$ de Imunologia/FIOCRUZ. Av. Brasil 4365, 21045-900 Rio de Janeiro, RJ, Brazil. Tel: 552125984551 . Fax: 552122801589

e-mail:mendonca@ioc.fiocruz.br

Recebido para publicação em 5/11/2001
} 
schedule used consisted of three ten-day cycles of $15 \mathrm{mg}$ of $\mathrm{Sb} /(\mathrm{kg} . \mathrm{d})$ with a maximum daily dose of $850 \mathrm{mg}$ $\mathrm{Sb}$. Using this regimen, complete resistance to antimonial therapy has never been observed. A minority of patients required additional cycles but eventually all of them were cured without using second-line drugs. In the municipality of Rio de Janeiro, the disease is exclusively due to $L$. braziliensis ${ }^{15}$. Although this species is the main causative agent of mucocutaneous leishmaniasis ${ }^{10}$, secondary metastatic mucosal lesions are rare ${ }^{21}$. As the outpatient units are located close to the endemic areas and the local population possesses a good level of awareness about the disease, most of the patients start treatment one to three months after appearance of lesions ${ }^{21}$.
Since 1992, the Brazilian Ministry of Health recommends for the antimonial therapy of cutaneous leishmaniasis the dosage of $15 \mathrm{mg}$ of pentavalent antimony $(\mathrm{Sb}) /(\mathrm{kg} . \mathrm{d})$ for 20 days. In the outpatient units of the Municipal Secretariat of Health of Rio de Janeiro, the intermittent schedule was replaced by the continuous regimen on December 1995 . This study compares retrospectively the efficacy, adherence, frequency of side effects and time to cure provided by the two antimonial therapy schedules by reviewing a series of autochthonous cutaneous leishmaniasis cases diagnosed and treated by the same medical personnel from December 1993 to August 1998.

\section{PATIENTS AND METHODS}

Patients. All patients studied had localized cutaneous leishmaniasis without mucosal lesions and came from endemic areas located within the Rio de Janeiro municipality. The diagnosis was based on clinical, epidemiological, immunological (leishmanin skin test, considered positive when induration with a diameter greater than or equal to $5 \mathrm{~mm}$ was detectable $48 \mathrm{~h}$ after the injection, and detection of Leishmania-specific antibodies by indirect immunofluorescence and ELISA) and parasitological (direct visualization of amastigotes by microscopic examination of Giemsa-stained smears and isolation of the parasite in NNN medium) criteria, as described in detail elsewhere 2021 .

Therapeutic schedules. The drug employed in this study was Glucantime ( $\mathrm{N}$-methyl-glucamine antimoniate, Rhodia Farma Ltda, São Paulo, Brazil) supplied by the Brazilian Ministry of Health. Forty-nine patients were treated between December 1993 to December 1995, with the intermittent regimen consisting of daily doses of $15 \mathrm{mg}$ of $\mathrm{Sb}^{5+} /(\mathrm{kg} . \mathrm{d})$ via the intramuscular route, given in three ten-day cycles interposed with ten-day rest intervals. On January 1996, the intermittent schedule was replaced by the continuous schedule using the same daily doses during 20 consecutive days. From January 1996 to August 1998, seventy-one patients received the continuous schedule of antimonial therapy.
During the whole period which comprised this review (from 1993 to 1998), there was no substantial difference regarding the incidence or any other epidemiological feature of the disease in the study area.

Clinical management and follow-up. The clinical progression of all patients regarding response to therapy and appearance of adverse side effects was evaluated at weekly consultations by the same medical personnel until cure. Cure was defined as complete epithelialization of the lesions without any sign of inflammation including nodules, papules, erythema, edema, itching or scale. If cure was not achieved within three months after the end of either schedule, the treatment was either extended (with additional series in the case of the intermittent regimen) or repeated (in the case of the continuous schedule), and this was considered as therapeutic failure. Absence of return for a post-therapy evaluation of clinical cure was considered as loss to follow-up.

Ethic aspects. This research was approved by Comitê de Ética em Pesquisa - CEP/FIOCRUZ, Fundação Oswaldo Cruz, Brazilian Ministry of Health, protocol number: 050/98.

Statistical analysis. The Mann-Whitney test, $\mathrm{X}^{2}$ test for independence and Fisher's exact test were used for statistical analysis. All tests were two-tailed, and probability values less than 0.05 were considered significant.

\section{RESULTS}

Similarity between the study groups with regard to demographic characteristics and clinical presentation. No significant difference could be observed between the composition of the study groups with respect to sex and age. Thirty-eight $(53.5 \%)$ of the 71 patients receiving the continuous schedule were male and the other 33 (46.5\%) were female. Among the 49 patients who received the intermittent regimen, 31 $(63.3 \%)$ were male and $18(36.7 \%)$ female. The patients mean $( \pm S D)$ age was $27.5( \pm 18.8)$ years for the group receiving the continuous regimen and $32.7( \pm 19.9)$ years for the group receiving the intermittent schedule.

Moreover, the study groups showed similar composition with regard to clinical features. All patients had a positive leishmanin skin test. The period of disease progression before onset of therapy was $2( \pm 1.3)$ months for the continuous and $2.5( \pm 1.6)$ months for the intermittent regimen. Fifty-one $(71.8 \%)$ patients from the group receiving continuous treatment had single lesions, whereas in the group receiving intermittent therapy 32 $(65.3 \%)$ had single lesions. In both groups, the legs were the most frequent lesion site $(49.3 \%$ of the cases for the group receiving continuous therapy and $45.3 \%$ for the group with intermittent therapy), followed by the arms, head and trunk (respectively $24.7 \%, 18.2 \%$ and $7.8 \%$ for the group with continuous therapy and $28.3 \%$, $15.1 \%$ and $11.3 \%$ for the group with intermittent therapy). The typical cutaneous leishmaniasis ulcer was the most 
frequent aspect of the cutaneous lesions. Sixty-four $(90.1 \%)$ patients from the continuous therapy group had exclusively ulcerated lesions, while in the intermittent therapy group, patients with ulcerated lesions alone were forty-three (87.8\%).

Clinical outcome of the patients receiving continuous or intermittent antimonial therapy schedules. Patients in either group were classified with respect to their clinical progression as cure, therapeutic failure or loss to follow-up according to the above defined criteria (Table 1). The cure rate was significantly higher in the group receiving the intermittent therapy than in the group receiving the continuous schedule (OR=0.20, 95\% Cl $0.07-0.56, p=0.001$ ). Therapeutic failure was observed in $6.1 \%$ of the subjects undergoing the intermittent regimen and in $16.9 \%$ of the group receiving the continuous schedule, but this difference was not significant $(\mathrm{OR}=3.12$, $95 \% \mathrm{Cl} 0.83-11.71, \mathrm{p}=0.10)$. Loss to follow-up was significantly more frequent in the group receiving the continuous schedule than in the intermittent schedule group $(\mathrm{OR}=5.77,95 \% \mathrm{Cl} 1.248-26.695, \mathrm{p}=0.01)$.
Considering exclusively those patients who returned for follow-up reevaluation, the cure rate was again significantly higher in the group that received the intermittent regimen than in the continuous therapy group $(93.6 \%$ vs $78.9 \%$; $\mathrm{OR}=0.26 ; 95 \% \mathrm{Cl} 0.07-0.97, \mathrm{p}<0.05)$. The period elapsed between onset of therapy and complete lesion healing could be established with an accuracy of one week interval for most of these patients (47 out of the 59 in the group taking the continuous schedule and 40 out of the 47 from the intermittent schedule group) and did not differ between the groups: $107.5 \pm 63.1$ days for the continuous and $103.6 \pm 53.9$ days for the intermittent schedule.

Adverse effects were observed in eight (16.3\%) patients under intermittent schedule and in 17 (23.9\%) patients under continuous regimen, and these values were not significantly different. The most frequent symptoms observed were myalgia, exanthema, arthralgia and local inflammatory reactions.

Table 1 - American cutaneous leishmaniasis patients who received either continuous or intermittent regimens of antimonial therapy, classified according to the clinical outcome.

\begin{tabular}{|c|c|c|c|c|c|c|c|c|}
\hline \multirow{2}{*}{$\begin{array}{l}\text { Antimonial } \\
\text { therapy schedule }\end{array}$} & \multicolumn{2}{|c|}{ Cure* $^{*}$} & \multicolumn{2}{|c|}{ Therapeutic failure } & \multicolumn{2}{|c|}{ Loss to follow-up ${ }^{\star *}$} & \multicolumn{2}{|c|}{$\begin{array}{l}\text { Total number of subjects } \\
\text { in each group } \\
\end{array}$} \\
\hline & $\mathrm{nr}$ & $\%$ & $\mathrm{nr}$ & $\%$ & $\mathrm{nr}$ & $\%$ & $\mathrm{nr}$ & $\%$ \\
\hline Intermittent & 44 & 89.8 & 3 & 6.1 & 2 & 4.1 & 49 & 100.0 \\
\hline Continuous & 45 & 63.4 & 12 & 16.9 & 14 & 19.7 & 71 & 100.0 \\
\hline
\end{tabular}

${ }^{*} \mathrm{OR}=0.20,95 \% \mathrm{Cl} 0.07-0.56, \mathrm{p}=0.001$ (Fisher's exact test).

** $\mathrm{OR}=5.77,95 \% \mathrm{Cl} 1.248-26.695, \mathrm{p}=0.01$ (Fisher's exact test).

\section{DISCUSSION}

The intermittent regimen of ten-day courses of antimonial therapy interrupted by ten-day intervals ${ }^{16}$, recommended by the manufacturers of the antimonial drugs used in leishmaniasis, has been widely used in Brazil with success ${ }^{14}$. We evaluated the impact of the substitution of this intermittent regimen by the continuous therapy, currently recommended by the Brazilian Ministry of Health, in outpatient units located in the municipality of Rio de Janeiro, with regard to efficacy, adherence, frequency of side effects and the time to cure cutaneous leishmaniasis caused by L. braziliensis. For this purpose, we studied two groups of patients that were treated in the same outpatient units by the same medical personnel: one group with the intermittent regimen between December 1993 and December 1995 and the other one with the continuous schedule between January 1996 and August 1998. The groups showed similar composition regarding age, sex and clinical condition, including duration of disease and number, aspect and localization of cutaneous lesions. All the parasites isolated from the study patients and submitted to analysis by enzyme electrophoresis ${ }^{6}$ were characterized as $L$. braziliensis (data not shown). All patients studied had exclusively cutaneous lesions.
Patients with mucosal lesions treated during the study period were excluded from the study because mucosal leishmaniasis is an exceptional clinical form in the area and has a higher tendency to relapse than cutaneous leishmaniasis ${ }^{19}$. Both study groups reflected the common profile of the disease seen in Rio de Janeiro: most patients had less than three months of disease, one or few lesions and the typical ulcer was the most common disease presentation ${ }^{21} 24$.

The time elapsed between start of therapy and complete lesion healing could be accurately estimated for most patients in both groups and was similar to previous reports on cutaneous leishmaniasis due to L. braziliensis in Brazil ${ }^{14}$. Both schedules resulted in cure rates within the range found in previous studies on antimonial therapy of American cutaneous leishmaniasis ${ }^{12}{ }^{23}$ and no difference was observed between the groups in this regard. However, the intermittent schedule provided a significantly higher cure rate when compared to the continuous schedule, even when we considered exclusively the patients who completed treatment and returned to follow-up.

One of the arguments against the discontinuous antimonial treatment ${ }^{12}$ has been the finding that both 
sodium stibogluconate and meglumine antimoniate are rapidly excreted in the urine ${ }^{5}$. The supporters of this argument have probably overlooked a series of important and consistent observations: a) most of the rapidly excreted antimony in the urine is pentavalent ${ }^{8}$, b) pentavalent antimony is reduced to the trivalent state in vivo ${ }^{82}$, c) trivalent antimony can accumulate in livers from animals injected with pentavalent antimonials ${ }^{8}, d$ ) trivalent antimonials are much more active against both promastigotes and amastigotes than pentavalent compounds 222526 . Taken together, these data indicate that, although most of the pentavalent antimony is rapidly excreted by the kidneys, the parasiticidal effect of the drug is probably dependent on the proportion of slowly excreted trivalent antimony that is generated and accumulated in vivo ${ }^{25}$. It has been shown that amastigotes inside macrophages had a higher antimony content six days after a single $4 \mathrm{~h}$ treatment than they did immediately after treatment, suggesting that macrophages may act as a reservoir for antimonial agents, prolonging parasite exposure to the drug ${ }^{25}$. In fact, we have observed by weekly examination of the patients that the progression of the cutaneous lesions towards healing during the rest intervals is indistinguishable from that observed during the periods of application of the drug. Moreover, most of the patients seen at the end the continuous therapy schedule still had open ulcers that progressed to heal thereafter (data not shown). Interestingly, when different schedules of intralesional treatment of Old World cutaneous leishmaniasis were compared, the weekly schedule was significantly more effective than daily treatment ${ }^{27}$. Another argument against the interrupted schedule is the supposition that the rest intervals could contribute to generate resistance. This presumption has not been based on clinical evidence and has minor relevance in areas where resistance to antimonial therapy is not seen in human leishmaniasis, like the study area. Nevertheless, it should be considered that a full intermittent regimen comprising 30 injections is more expensive than the continuous schedule of 20 injections.

In spite of being longer, the intermittent schedule provided higher adherence than the continuous regimen. The higher rate of loss to follow-up in the group receiving continuous therapy could be related to intolerance to a longer period of daily injections. However, we did not find significant differences between the two schedules regarding incidence of side effects, at least in the patients who completed therapy, and those side effects were never severe enough to recommend interruption of treatment. We do not know if the patients who did not return for post-therapy reevaluation actually interrupted the treatment or completed the prescribed schedule.
Although the application of the antimonial injections could be done in the outpatient units where this study was performed, most of the patients had transport difficulties and therefore preferred to take home the antimonial ampoules to be administered in their neighborhood. In the case of the intermittent treatment, they received the amount of ampoules needed for a tenday series and had to return in order to continue therapy. This is a possible cause for the better adherence observed with this regimen. On the other hand, the patients who took the continuous schedule received all the antimonial ampoules for a full twenty-day treatment. In this case, it is possible that some patients, having received a full treatment and noticing the improvement of their clinical condition, did not consider that a follow-up consultation after treatment would be important. Whatever the reason, medical reevaluation to confirm cure and completion of treatment is particularly necessary in the case of cutaneous leishmaniasis caused by $L$. braziliensis. This species is the main causative agent of mucosal leishmaniasis, a severe clinical form that can develop a long time after healing of the primary cutaneous lesions ${ }^{19}$. Higher risk of development of secondary mucosal lesions and relapse of cutaneous leishmaniasis has been associated with incomplete or inadequate treatment of American cutaneous leishmaniasis ${ }^{14} 19$.

Clinical trials using $\mathrm{Sb}$ compounds in a variety of therapeutic schedules have been done with cutaneous, mucocutaneous and visceral leishmaniasis patients from diverse populations in many countries. Frequently, observations made in studies on visceral leishmaniasis were used as guidelines to design therapeutic schedules for cutaneous leishmaniasis. In particular, the suppression of rest intervals has been justified by studies performed with visceral leishmaniasis in Kenya ${ }^{2}{ }^{28}$, where both visceral and cutaneous leishmaniases were considered as poorly responsive to antimonial therapy ${ }^{13}$. This is not the case in Brazili ${ }^{17}$. Different species and strains of Leishmania exhibit a broad spectrum of sensitivity to pentavalent antimonials both clinically and in vitro ${ }^{31123}$. Cutaneous leishmaniasis caused by L. braziliensis in Rio de Janeiro State responds relatively well to antimonial therapy, even with low dosage regimens ${ }^{24}$.

The present data do not support the conclusion that the use of rest intervals would be better than continuous therapy for all forms of human leishmaniasis. However, they show that, in an endemic area of cutaneous leishmaniasis caused by $L$. braziliensis where specialized medical care and specific treatment are readily available and total resistance to antimonial therapy does not exist, the effectiveness and adherence provided by the intermittent regimen were significantly higher than those of the continuous regimen.

\section{ACKNOWLEDGEMENTS}

We are grateful to Drs. Rachel Tardin e Valéria Esteves from Secretaria Municipal de Saúde do Rio de Janeiro for administrative support. 


\section{REFERENCES}

1. Anabwani GM, Nigra JA, Dimiti G, Bryceson ADM. Comparison of two dosage schedules of sodium stibogluconate in the treatment of visceral leishmaniasis in Kenya. Lancet 1:210-213, 1983.

2. Berman JD. Chemotherapy for leishmaniasis: biochemical mechanisms, clinical efficacy, and future strategies. Reviews of Infectious Diseases 10: 560-586, 1988.

3. Berman JD, Chulay JD, Hendricks LD, Oster CN. Susceptibility of clinically sensitive and resistant Leishmania to pentavalent antimony in vitro. American Journal of Tropical Medicine and Hygiene 31: 459-465, 1982.

4. Chulay JD, Anzeze EM, Kohch DK, Bryceson ADM. High and low sodium stibogluconate treatment of cutaneous leishmaniasis in Kenya. Transactions of the Royal Society of Tropical Medicine and Hygiene 77: 717-721, 1983.

5. Chulay JD, Fleckenstein L, Smith DH. Pharmacokinetics during treatment of visceral leishmaniasis with sodium stibogluconate or meglumine antimoniate. Transactions of the Royal Society of Tropical Medicine and Hygiene 82: 69-72, 1988.

6. Cupolillo E, Grimaldi Jr G, Momen H. A general classification of New World Leishmania using numerical zymotaxonomy. American Journal of Tropical Medicine and Hygiene 50: 296-311, 1994

7. Gasser RA Jr, Magill AJ, Oster CN, Franke ED, Grogl M, Berman JD. Pancreatitis induced by pentavalent antimonial agents during treatment of leishmaniasis. Clinical Infectious Diseases 18: 83-90, 1994.

8. Goodwin LG, Page JE. A study of the excretion of organic antimonials using a polarographic procedure. Biochemical Journal 22: 236-240, 1943.

9. Grimaldi Jr G, David JR, McMahon-Pratt D. Identification and distribution of New World Leishmania species characterized by serodeme analysis using monoclonal antibodies. American Journal of Tropical Medicine and Hygiene 36: 270-287, 1987.

10. Grimaldi Jr G, Tesh RB. Leishmaniasis of the New World: current concepts and implications for future research. Clinical and Microbiology Reviews 6: 230-250, 1993.

11. Grögl M, Oduola AMJ, Cordere LDC, Kyle DE. Leishmania spp: development of pentostam-resistant clones in vitro by discontinuous drug exposure. Experimental Parasitology 69: 78-90, 1989.

12. Guderian $\mathrm{RH}$, Chico ME, Rogers MD, Pattishal KM, Grögl M, Berman JD. Placebo controlled treatment of Ecuadorian cutaneous leishmaniasis. American Journal of Tropical Medicine and Hygiene 45: 92-97, 1991.

13. Guimarães MC, Celeste BJ, Franco EL. Diagnostic performance indices for immunofluorescence and enzyme immunoassays of leishmaniasis sera from northern and north-eastern Brazil. Bulletin of the World Health Organization 68: 39-43, 1990.

14. Llanos-Cuentas EA, Marsden PD, Lago EL, Barreto AC, Cuba CC, Johnson WD. Human mucocutaneous leishmaniasis in Três Braços, Bahia - Brazil. An area of Leishmania braziliensis braziliensis transmission. II. Cutaneous disease. Presentation and evolution. Revista da Sociedade Brasileira de Medicina Tropical 17: 169-177, 1984.

15. Lopes UG, Momen H, Grimaldi G Jr, Marzochi MCA, Pacheco R, Morel CM. Schizodeme and zymodeme characterization of
Leishmania in the investigation of foci of visceral and cutaneous leishmaniasis. Journal of Parasitology 70: 89-98, 1984

16. Manson-Bahr PEC 1959. East African kala-azar with special reference to the pathology, prophylaxis and treatment. Transactions of the Royal Society of Tropical Medicine and Hygiene 53: 123-37, 1959.

17. Marsden PD. New light on pentavalent antimonials in the treatment of leishmaniasis. Revista do Instituto de Medicina Tropical de São Paulo 16: 172-174, 1983

18. Marsden PD. Pentavalent antimonials: old drugs for new diseases. Revista da Sociedade Brasileira de Medicina Tropical 18: 187-198, 1985.

19. Marsden PD. Mucosal leishmaniasis ("espundia" Escomel, 1911). Transactions of the Royal Society of Tropical Medicine and Hygiene 80: 859-876, 1986.

20. Mendonça SC, Coutinho SG, Amendoeira RR, Marzochi MCA, Pirmez C. Human American cutaneous leishmaniasis (Leishmania b. braziliensis) in Brazil: lymphoproliferative responses and influence of therapy. Clinical Experimental Immunology 64: 269276, 1986

21. Mendonça SCF, Souza WJS, Nunes MP, Marzochi MCA Coutinho SG. Indirect immunofluorescence test in New World leishmaniasis: serological and clinical relationship. Memórias do Instituto Oswaldo Cruz 83: 347-355, 1988.

22. Mottram JC, Coombs GH. Leishmania mexicana: enzyme activities of amastigotes and promastigotes and their inhibition by antimonials and arsenicals. Experimental Parasitology 59: 235-242, 1985.

23. Navin TR, Arana BA, Arana FE, Berman JD, Chajon JF. Placebocontrolled clinical trial of sodium stibogluconate (Pentostam) versus ketoconazole for treating cutaneous leishmaniasis in Guatemala. Journal of Infectious Diseases 165: 528-534, 1992.

24. Oliveira-Neto MP, Schubach A, Mattos M, Gonçalves-Costa SC Pirmez C. A low-dose antimony treatment in 159 patients with American cutaneous leishmaniasis: extensive follow-up studies (up to 10 years). American Journal of Tropical Medicine and Hygiene 57: 651-655, 1997.

25. Roberts WL, Berman JD, Rainey PM. In vitro antileishmanial properties of tri- and pentavalent antimonial preparations. Antimicrobial Agents and Chemotherapy 39: 1234-1239, 1995.

26. Roberts WL, Rainey PM. Antimony quantification of sodium stibogluconate fractions. Antimicrobial Agents and Chemotherapy 37: 1842-1846, 1993.

27. Tallab TM, Bahamdam KA, Mirdad S, Johargi H, Mourad MM, Ibrahim K, el Sherbini AH, Karkashan E, Khare AK, Jamal A Cutaneous leishmaniasis: schedules for intralesional treatment with sodium stibogluconate. International Journal of Dermatology 8: 594-597, 1996

28. Wijers DJ. A 10-year study of kala-azar in Tharaka (Meru district, Kenya). II. Relapses. East African Medical Journal 48: 551-558, 1971.

29. Yarbuh AL, Anez N, Pena YP, Burguera JL, Burguera M. Antimony determination in tissues and serum of hamsters infected with meglumine antimoniate. Annals of Tropical Medicine and Parasitology 88: 37-41, 1994. 